\title{
Video Article \\ A High-Throughput Electrochemiluminescence 7-Plex Assay Simultaneously Screening for Type 1 Diabetes and Multiple Autoimmune Diseases
}

\author{
Xiaofan $\mathrm{Jia}^{\star^{1,2}}$, Ling $\mathrm{He}^{\star^{1,3}}$, Yong Gu ${ }^{1}$, Hilary High ${ }^{1}$, Liping Yu ${ }^{1}$ \\ ${ }^{1}$ Barbara Davis Center for Diabetes, University of Colorado School of Medicine \\ ${ }^{2}$ Department of Endocrinology, Beijing Hospital, National Center of Gerontology; Institute of Geriatric Medicine, Chinese Academy of Medical Sciences \\ ${ }^{3}$ Department of endocrinology, Guangzhou First People's Hospital, School of Medicine, South China University of Technology \\ * These authors contributed equally
}

Correspondence to: Liping Yu at LIPING.YU@cuanschutz.edu

URL: https://www.jove.com/video/61160

DOI: doi:10.3791/61160

Keywords: Medicine, Issue 159, electrochemiluminescence assay, multiplex autoantibody assay, type 1 diabetes, autoimmune disease, screening, prediction

Date Published: 5/29/2020

Citation: Jia, X., He, L., Gu, Y., High, H., Yu, L. A High-Throughput Electrochemiluminescence 7-Plex Assay Simultaneously Screening for Type 1 Diabetes and Multiple Autoimmune Diseases. J. Vis. Exp. (159), e61160, doi:10.3791/61160 (2020).

\section{Abstract}

Islet autoantibodies (IAbs) are widely used in type 1 diabetes (T1D) diagnosis and prediction. Four major IAbs to insulin (IAA), glutamate decarboxylase-65 (GADA), insulinoma antigen-2 (IA-2A), and zinc transporter-8 (ZnT8A) are equally important in disease prediction. Presently, up to $40 \%$ of patients diagnosed with T1D go on to develop other autoimmune disorders. Unfortunately, current screening methods using a single autoantibody for measurement are laborious and inefficient for large scale screening studies. We recently developed a simple multiplexed electrochemiluminescence (ECL) assay to address these current issues. The assay combines all 7 autoantibody tests into one well. Each well includes three IAbs (IAA, GADA, and IA-2A), autoantibodies to thyroid peroxidase (TPOA) and thyroid globulin (ThGA) to detect autoimmune thyroid disease, autoantibodies to tissue transglutaminase (TGA) for celiac disease, and autoantibodies to interferon alpha (IFNaA) for autoimmune polyglandular syndrome-1 (APS-1); all of which screen for T1D and other relevant autoimmune diseases, simultaneously. The multiplex ECL assay is based on the single ECL assay platform, but instead uses the multiplex plate combining multiple autoantibody assays, up to 10 , into a single well. The main difference from the single ECL assay is that each antibody-antigen complex formed in the fluid-phase is restrained onto a specific spot on each well through a linker system on the multiplex plate. The 7-Plex ECL assay, in the present study, is validated against standard radio-binding assays (RBA) and single ECL assays, using a large cohort of newly diagnosed T1D patients and agematched healthy controls, resulting in excellent assay sensitivity and specificity.

\section{Introduction}

Type 1 diabetes (T1D) is a serious chronic disease that is most common at the childhood. Currently, around 1.4 million people have the T1D in the United States; strikingly, the incidence of T1D is steadily increasing at 3-5\% each year worldwide and has doubled in the last two decades, especially in young children ${ }^{1,2}$. Islet autoantibodies (IAbs) in blood circulation are the most reliable biomarker at present. The IAbs may appear years before clinical T1D develops ${ }^{3}$. Currently, four major IAbs are widely used in T1D diagnosis and risk screening including autoantibodies to insulin (IAA), glutamate decarboxylase-65 (GADA), insulinoma antigen-2 (IA-2A), and zinc transporter-8 (ZnT8A). These four IAbs are equally important in prediction of T1D development. The classification of T1D has been re-defined recently as the presence of $\geq 2$ of any 4 IAbs with a normal glucose metabolism as the disease stage $1^{4}$.

In the Diabetes Autoimmunity Study in the Young (DAISY), it was revealed that one in four children at risk for T1D were likely to progress to islet, celiac, thyroid or rheumatoid autoimmunity and more strikingly, approximately $40 \%$ of patients who have been diagnosed with T1D eventually develop an additional autoimmune condition ${ }^{5,6,7}$. Identification of autoantibodies are essential for prediction and diagnosis of these autoimmune diseases and should provide better clinical care for patients. There is no easy and inexpensive way at present to screen for these multiple autoimmune conditions. Current screening methods using standard radio-binding assay (RBA), with a single autoantibody measurement, are laborious and inefficient for a largescale screening.

Here, we will be describing the newly developed simple multiplexed ECL assay, which we have authenticated using a single ECL assay platform $8,9,10,11$. The multiplex ECL assay combines 7 autoantibody tests into a single well, using only $15 \mu \mathrm{L}$ of serum, and is capable of screening for T1D and multiple relevant autoimmune diseases simultaneously including celiac disease, autoimmune thyroid disease, and APS-1. A ZnT8A ECL assay had not been developed at the time and was not included in the multiplexed assay. The multiplex ECL assay provides an excellent tool for high throughput in general population screening for T1D and multiple autoimmune diseases.

\section{Protocol}

The research protocol was approved by the Colorado Multiple Institutional Review Board. 


\section{Buffer preparation}

1. Make the labeling buffer (2x PBS, $\mathrm{pH} 7.9$ ). Using $400 \mathrm{~mL}$ of distilled deionized (DD) water, add $100 \mathrm{~mL}$ of $10 x$ PBS. To adjust the pH of the solution, add $\mathrm{NaOH}$ until it reaches 7.9 .

2. Create $3 \mathrm{mM}$ biotin by dissolving $1 \mathrm{mg}$ of biotin into $588 \mu \mathrm{L}$ of labeling buffer previously created. Make $3 \mathrm{mM}$ Ru Sulfo-NHS by dissolving 150 $\mathrm{nmol}$ of Ru Sulfo-NHS into $50 \mu \mathrm{L}$ of labeling buffer.

3. Make the antigen buffer (1\% BSA) by taking $500 \mathrm{~mL}$ of $1 \times \mathrm{PBS}$ and adding $5 \mathrm{~g}$ of bovine serum albumin (BSA) to the solution. Prepare $0.5 \mathrm{M}$ of acetic acid solution. Prepare $1 \mathrm{M}$ Tris- $\mathrm{HCl}$ buffer using Trizma Base and adjusting the $\mathrm{pH}$ to 9.0 .

4. For the coating buffer ( $3 \%$ Blocker $\mathrm{A})$, take $500 \mathrm{~mL}$ of $1 \times$ PBS and add $15 \mathrm{~g}$ of Blocker A. Prepare the washing buffer (0.05\% Tween 20 , PBST) by mixing $5000 \mathrm{~mL}$ of $1 \times$ PBS with $2.5 \mathrm{~mL}$ of Tween 20. Create reading buffer (2x Read Buffer T with surfactant) by adding $500 \mathrm{~mL}$ of $\mathrm{DD}$ water and $500 \mathrm{~mL}$ of $4 \mathrm{x}$ Read Buffer T with Surfactant.

NOTE: To keep consistency between assays it is important that both the biotin and Ru Sulfo-NHS solutions are created just before the labeling procedure and are not created and stored for future use.

\section{Labeling each antigen protein with biotin and Ru Sulfo-NHS separately}

NOTE: To have a more effective labeling reaction, use an antigen protein concentration of $\geq 0.5 \mathrm{mg} / \mathrm{mL}$.

1. Calculate the molar number of each antigen protein and the molar numbers of the biotin and Ru Sulfo-NHS. Add a proper amount of biotin or $\mathrm{Ru}$ Sulfo-NHS to antigen protein for labeling reaction according to the molar ratio of antigen protein to biotin or Ru Sulfo-NHS.

1. For the antigen that has the smaller molecular weight $(\leq 10 \mathrm{kDa})$, such as proinsulin protein, use a molar ratio of 1:5 (antigen: biotin and Ru Sulfo-NHS). For the antigen that has the larger molecular weight (>50 kDa), such as GAD protein, use a molar ratio of 1:20. For the antigen that has a middle molecular weight (10-50 kDa), use a molar ratio adjusted between 1:5-1:20.

2. For both the biotin and Ru Sulfo-NHS, divide each antigen weight by their corresponding molecular weights to get the antigen molar number for each one. Divide the molar number by the concentration to get the volume for biotin. Repeat this for Ru Sulfo-NHS.

3. Mix the antigen protein with biotin using the proper molar ratio, determined in step 2.2. Then do the same for Ru Sulfo-NHS. NOTE: For efficiency of labeling reaction, any reducing chemicals like Tris or glycine in the buffer system need to be exchanged to $2 x$ PBS buffer, $\mathrm{pH} 7.9$ by the sizing spin column. The labeling protocols for biotin and Ru Sulfo-NHS are identical.

4. Cover the reaction tubes with aluminum foil and incubate them at room temperature (RT) for $1 \mathrm{~h}$. The reason covering the reaction tubes with foil is because both biotin and Ru Sulfo-NHS reagents are light sensitive.

5. Prime the $2 \mathrm{~mL}$ or $5 \mathrm{~mL}$ spin column while the reaction tubes are incubating (the size of spin column is determined by the volume uploaded onto the column). Fill the spin column with $2 \times$ PBS buffer and then centrifuge it at 1,000 $\mathrm{g} g$ for 2 min each time, for a total of three times.

6. Stop the labeling reaction after the reaction tubes have finished incubating. To stop the reaction, purify the labeled antigen protein by passing it through the spin column once. Then centrifuge the column at 1,000 $\mathrm{xg}$ for $2 \mathrm{~min}$.

7. Calculate the total labeled antigen concentration by dividing the amount of antigen protein present by the final volume. Aliquot $50 \mu \mathrm{L}$ of the purified labeled antigen protein per tube and store the aliquots at $-80^{\circ} \mathrm{C}$ for long term use. NOTE: It is important to be aware that for every time the spin column passes the antigen protein through, there will be about a $90-95 \%$ retention rate.

\section{Define the best concentration and ratios for the two labeled antigens for the assay (checkerboard assay)}

NOTE: Since the ECL-IAA assay in this 7-Plex assay requires acid treatment of serum samples, the checkerboard assay for each antigen has to go through this step before incubating with the labeled antigen mixture.

1. Apply the checkerboard assay for each antigen separately before running the multiplex assay. Steps 3.2-3.6 will use GAD65 as an example.

2. Calculate dilution of labeled GAD65 protein. The recommended targeted concentration of the first mixture solution of biotinylated GAD65 is $2000 \mathrm{ng} / \mathrm{mL}$ and Ru Sulfo-NHS labeled GAD65 is $1000 \mathrm{ng} / \mathrm{mL}$. If the concentration of both biotinylated and Ru Sulfo-NHS labeled GAD65 in stock solution are $1.0 \mu \mathrm{g} / \mu \mathrm{L}$, the volume needed for biotinylated GAD65 in $560 \mu \mathrm{L}$ of working solution will be $1.12 \mu \mathrm{L}$, and the volume needed for Ru Sulfo-NHS labeled GAD65 in $700 \mu \mathrm{L}$ of working solution will be $0.7 \mu \mathrm{L}$.

3. Mix $1.12 \mu \mathrm{L}$ of biotinylated GAD65 protein with $240 \mu \mathrm{L}$ of streptavidin-conjugated linker 1 in one tube and $160 \mu \mathrm{L}$ of $1 \%$ BSA. Incubate the mixture at room temperature for $30 \mathrm{~min}$. Add $160 \mu \mathrm{L}$ of stop solution to the tube and incubate the mixture at room temperature for another 30 $\min$.

4. Make a serial dilution. Take $280 \mu \mathrm{L}$ of the mixture to a new tube and add $280 \mu \mathrm{L}$ of stop solution to make a 1:2 dilution. Prepare several new tubes. Repeat this step to run a horizontal serial dilution for biotin labeled GAD65 antigen (refer to the previous publication ${ }^{12}$ ).

5. Mix $0.7 \mu \mathrm{L}$ of Ru Sulfo-NHS labeled GAD65 $(1 \mu \mathrm{g} / \mu \mathrm{L})$ protein with $700 \mu \mathrm{L}$ of stop solution. Then take $350 \mu \mathrm{L}$ of the mixture to a new tube and add $350 \mu \mathrm{L}$ of stop solution to make a 1:2 dilution. Prepare several new tubes, repeat this step to run a vertical serial dilution for Ru SulfoNHS labeled GAD65 antigen.

6. Prepare two serum samples, one sample highly positive for GADA and one sample negative for GADA, each having a volume of $0.75 \mathrm{~mL}$. Aliquot $15 \mu \mathrm{L}$ of positive serum into every well on the left half of the 96-well PCR plate. Aliquot $15 \mu \mathrm{L}$ of negative serum into every well on the right half of the 96-well PCR plate.

7. Add $18 \mu \mathrm{L}$ of $0.5 \mathrm{M}$ acetic acid into each well and mix. Incubate for $45 \mathrm{~min}$ at RT. Prepare a new 96 -well PCR plate. Add $17.5 \mu \mathrm{L}$ of the biotin labeled antigen and $17.5 \mu \mathrm{L}$ of the Ru Sulfo-NHS labeled antigen into each well according to the serial dilutions (refer to the previous publication ${ }^{12}$ ).

8. Continue the rest of the assay steps described in step 5.2 through 9.1 . 
9. Determine the signal ratio from the high positive samples against the corresponding negative sample signals. Select the best concentration for the Biotin labeled antigen and the Ru Sulfo-NHS labeled antigen by identifying the point that has the highest or near to the highest ratio of positive to negative signal. In this ratio calculation, consider the low background signal obtained from the negative samples. NOTE: The optimal concentrations of Ru Sulfo-NHS and biotin labeled antigen proteins from checkerboard assays are shown below: 30 ng/ $\mathrm{mL}$ and $200 \mathrm{ng} / \mathrm{mL}$ for GAD65, $120 \mathrm{ng} / \mathrm{mL}$ and $120 \mathrm{ng} / \mathrm{mL}$ for proinsulin, $10 \mathrm{ng} / \mathrm{mL}$ and $42 \mathrm{ng} / \mathrm{mL}$ for IA-2, $80 \mathrm{ng} / \mathrm{mL}$ and $80 \mathrm{ng} / \mathrm{mL}$ for TG, 8 $\mathrm{ng} / \mathrm{mL}$ and $16 \mathrm{ng} / \mathrm{mL}$ for TPO, $31 \mathrm{ng} / \mathrm{mL}$ and $31 \mathrm{ng} / \mathrm{mL}$ for ThG, and $12 \mathrm{ng} / \mathrm{mL}$ and $12 \mathrm{ng} / \mathrm{mL}$ for IFNa.

\section{Create the mixed linker-coupled antigen solution}

1. Select the optimal concentration for each antigen based on the checkerboard assay. Dilute the biotin and Ru Sulfo-NHS labeled antigen to the rational working concentration.

2. Bind different linkers to each of the uniquely biotinylated antigen proteins. For one 96-well plate assay, mix $4 \mu \mathrm{L}$ of biotinylated GAD65, TPO, tTG, ThG, proinsulin, IFN- $\alpha$ and IA-2 protein with $240 \mu \mathrm{L}$ of streptavidin-conjugated linker 1, 2, 3, 4, 8, 9 and 10 into separate tube (Figure 1). Then add $156 \mu \mathrm{L}$ of $\mathrm{PBS} / 1 \%$ BSA per tube. Incubate the mixture at room temperature for $30 \mathrm{~min}$.

3. Add $160 \mu \mathrm{L}$ of stop solution into each tube and incubate them at room temperature for another 30 min. Take $400 \mu \mathrm{L}$ of linker-coupled antigen from each tube, and combine all 7 antigens together. Add $1.2 \mathrm{~mL}$ of stop solution and then add $4 \mu \mathrm{L}$ of Ru Sulfo-NHS labeled GAD65, TPO, tTG, ThG, proinsulin, IFN- $\alpha$ and IA-2 antigen to the mixture. Now the antigen solution is ready to be used in the assay.

\section{Incubate serum samples with the labeled antigen}

NOTE: Since the ECL-IAA assay in this 7-Plex assay requires acid treatment of serum samples, each serum requires the acid treatment step before incubating with labeled antigen mixture for this 7-Plex assay.

1. Aliquot $15 \mu \mathrm{L}$ of serum per well for a 96-well PCR plate. Add $18 \mu \mathrm{L}$ of $0.5 \mathrm{M}$ acetic acid into each well and mix. Incubate for $45 \mathrm{~min}$ at RT. Prepare a new $96-$ well PCR plate and aliquot $35 \mu \mathrm{L}$ of antigen solution into each well.

2. While the plate is still incubating, add $13 \mu \mathrm{L}$ of $1 \mathrm{M}$ Tris $\mathrm{pH} 9.0$ buffer to every well in the antigen plate. Add buffer to the side of each well to limit the mixing of Tris buffer and antigen. After incubation is complete, take $25 \mu \mathrm{L}$ of the acid treated serum, and immediately pipette it into every well on the antigen plate. Agitate the solution and cover the plate with PCR sealing foil to avoid light exposure.

3. At RT, put the plate on a shaker, set at a low speed, for $1 \mathrm{~h}$. Afterwards, store the plate at $4{ }^{\circ} \mathrm{C}$ and let the plate incubate for $18-24 \mathrm{~h}$.

\section{Prepare the multiplex plate}

1. Take a multiplex plate from the $4{ }^{\circ} \mathrm{C}$ refrigerator and allow the plate to come to $\mathrm{RT}$. Once the multiplex plate is at $\mathrm{RT}$, add $150 \mu \mathrm{L}$ of $3 \%$ Blocker $\mathrm{A}$ to each well. Cover the multiplex plate with sealing foil. Incubate the plate in a $4^{\circ} \mathrm{C}$ refrigerator overnight. NOTE: Assay Day 1 includes Steps 4 through 6.

\section{Transfer serum/antigen incubates into the multiplex plate}

1. The following day, place paper towels on the table and take the incubating multiplex plate from the refrigerator. Empty all of the buffer out of the plate. To do this, flip the plate upside down and pat it onto the prepared paper towels until there is no buffer present in any of the wells.

2. Wash the multiplex plate by adding $150 \mu \mathrm{L}$ of PBST into every well. Discard the buffer, as mention in step 7.1., and repeat this step three times. Add $30 \mu \mathrm{L}$ of serum/antigen incubates into every well in the multiplex plate. Cover the plate with foil to limit its exposure to light. Place the plate on a plate shaker, set to a low speed, at RT for $1 \mathrm{~h}$.

\section{Wash the plate and add read buffer}

1. Remove the serum/antigen incubates from the multiplex plate by holding the plate upside down and flicking out the solution. Add $150 \mu \mathrm{L}$ of PBST into all of the wells and remove the buffer from the plate by again holding the plate upside down and flicking out the solution. Repeat this step three times. After the third wash is complete, add $150 \mu \mathrm{L}$ of Reading buffer into each well.

NOTE: Air bubbles interfere with the plate reader machine's ability to accurately analyze the plate's results and should be avoided at all costs.

\section{Read the plate and analyze data}

1. Count the prepared plate on the plate reader machine, reading all of the values in counts per second (CPS).

2. Calculate the relative index for the assay, using the antibody levels obtained from the plate reader machine, with the following equation: Index value = [CPS (sample) - CPS (negative standard)] / [CPS (positive standard) - CPS (negative standard)].

3. Determine which antibody results are negative or positive using the cut-offs that have been established. NOTE: Assay Day 2 includes Steps 7 through 9.

\section{Representative Results}

Analysis of assay results was shown in Table 1, Table 2 and Table $\mathbf{3}$. Reading values come from the data from the 10 spots within the same well. Index values for each sample were calculated against their corresponding internal positive and negative controls as described in the assay protocol. Examples of bad duplicates are shown in Table 1 and caused the final index calculation error in Table 3. All raw counting values must be checked to avoid any false positive or false negative results. 
The 7-multiplexed ECL assay was validated using a large cohort of samples from 1026 newly diagnosed patients with T1D and 1022 age and sex matched healthy control subjects. The levels of autoantibodies from 7-Plex ECL assay for 1026 T1D patients were compared with the levels from each of our corresponding established single ECL assays as shown in Figure 2 and from each corresponding single standard RBA and ELISA as shown in Figure 3. The assay specificities were set up identical at $99^{\text {th }}$ percentiles for all autoantibody assays except for thyroid autoantibodies (where the 95th percentile was used), of 1022 healthy controls for all three assay methods (7-Plex ECL, single ECL, RBA or ELISA) as listed in Table 4. The inter-assay CVs of GADA, IA-2A, IAA, TPOA, ThGA, TGA, and IFNaA are $6.4 \%, 4.5 \%, 9.1 \%, 4.9 \%, 5.7 \%$, $11.3 \%$ and $5.9 \%$, respectively.

A small number of discordant samples for each of the 7 autoantibodies were found around the borderline of cut-offs for each assays (Figure 2 and Figure 3). Eleven control samples (11/1022, 1.1\%) were found multiple autoantibody positive only in the 7-Plex assay and negative in each corresponding single assay. Similarly, it happened in 9 samples of the T1D patients (9/1026, 0.9\%). In addition, 10 high positive TPOA and one ThGA in patient cohort that were seen in both the single ECL assay and RBA were missed in the 7-Plex assay. These samples were converted positive in the 7-Plex assay when they were further diluted. In general, $100 \%$ of positivity in single ECL assay or RBA were covered in the 7-Plex ECL assay, with the same assay specificity as illustrated in Table 4.

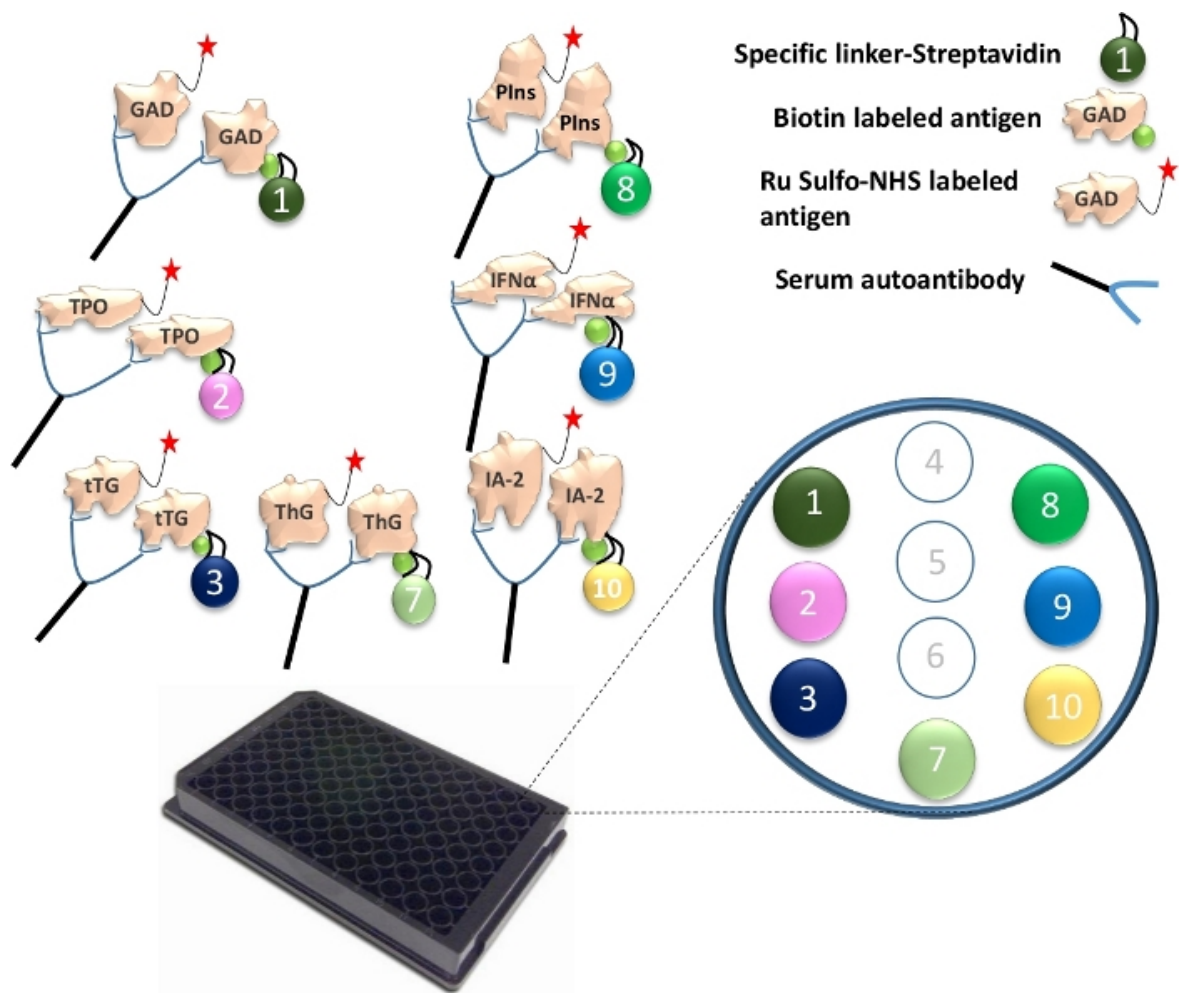

Figure 1: Illustration of the Mutiplex ECL assay.

Autoantibodies in serum will bridge the Ru Sulfo-NHSged antigen to the biotinylated antigen. This is coupled with a specific linker to form a complex of antigen-antibody-antigen-linker. The complexes are captured onto the plate and are restrained to their specific spots through each specific linker. The specifically coupled linker numbers, for the 7 different antigen proteins, are illustrated. Detection of antibody signals are accomplished using Ru Sulfo-NHS labeled antigens with electrochemiluminescence. The figure is from Gu, Y. et al. ${ }^{13}$. Please click here to view a larger version of this figure. 

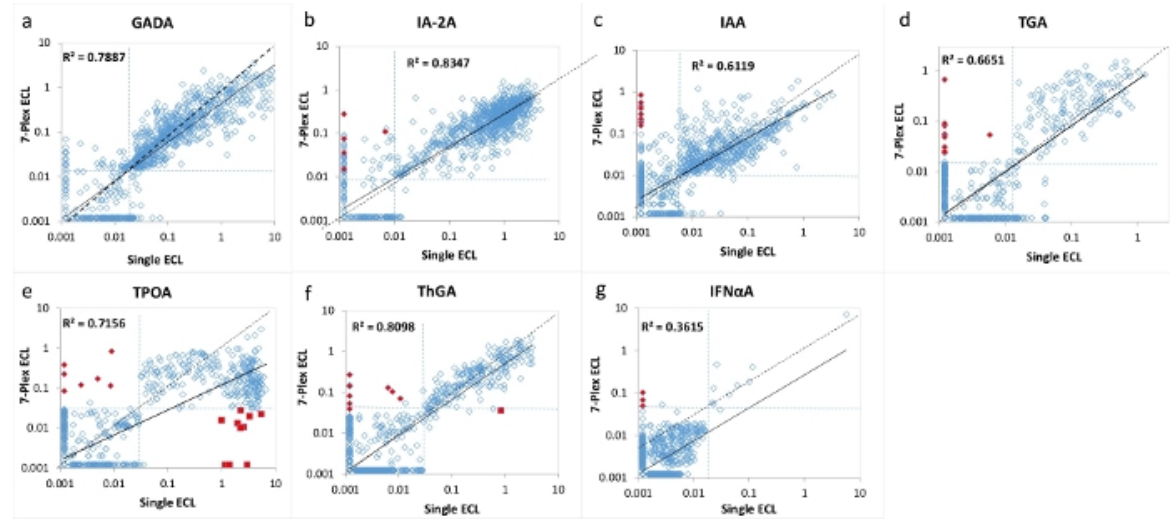

Figure 2: Comparison of 7 autoantibody levels in 1026 new onset patients with T1D between the single ECL assay and the 7-Plex ECL assay.

Panels a, b, c, d, e, f, and g display comparisons of autoantibody levels for GADA, IA-2A, IAA, TGA, TPOA, ThGA, and IFNaA, respectively. The dotted lines represent the assay cut-offs for each autoantibody assay. The cut-offs were set to the $99^{\text {th }}$ percentile of 1022 age-matched healthy controls for each assay (except for TPOA and ThGA which were set to the $95^{\text {th }}$ percentile), as shown in Table 4, from 1022 age matched healthy controls for both single and multiplex ECL assays. Red closed diamonds are marked as 'false' positives in the 7-Plex ECL assay, $<1 \%$ of the cohort studied, and they were validated as negative in both single ECL and RBA. Red close squares are marked as 'false' negatives in the 7Plex ECL assay caused by the 'prozone' phenomenon, mainly occurring in the TPOA assay in $<1 \%$ of the cohort studied. Both of these false positive and false negative outcomes are discussed in the discussion section. The figure is from Gu, Y. et al. ${ }^{13}$. Please click here to view a larger version of this figure.
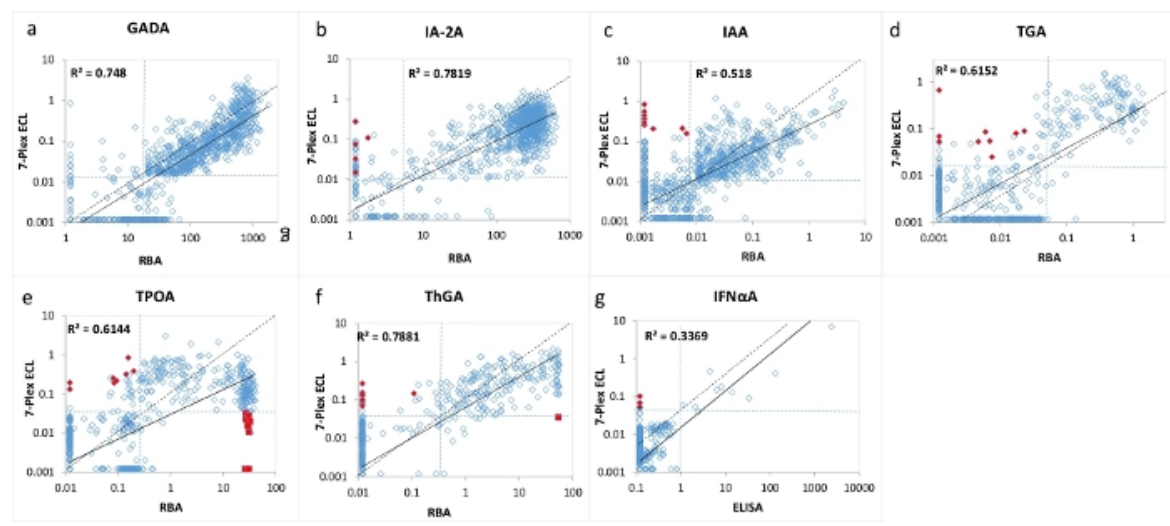

Figure 3: Comparison of 7 autoantibody levels in 1026 new onset patients with T1D between the RBA (ELISA for IFNaA) and the 7-Plex ECL assay.

Panels $a, b, c, d, e, f$, and g present comparisons of autoantibody levels for GADA, IA-2A, IAA, TGA, TPOA, ThGA, and IFNaA, respectively. The dotted lines represent the assay cut-offs for each autoantibody assay, the same specificity set for both RBA and the 7-Plex ECL assay, as shown in Table 4, from 1022 age matched healthy controls. Red closed diamonds and squares represent 'false' positives and 'false' negatives appearing in the 7-Plex ECL assay, the same is shown in Figure 2. The figure is from Gu, Y. et al. ${ }^{13}$. Please click here to view a larger version of this figure. 


\begin{tabular}{|c|c|c|c|c|c|c|c|}
\hline & 1 & 2 & 3 & 4 & 5 & 6 & \\
\hline \multirow[t]{10}{*}{ A } & 5580 & 5674 & 105 & 117 & 125 & 139 & linker-1 \\
\hline & 100 & 108 & 102 & 102 & 3956 & 3745 & linker-2 \\
\hline & 115 & 124 & 107 & 116 & 113 & 124 & linker-3 \\
\hline & 67 & 64 & 68 & 61 & 65 & 69 & linker-4 \\
\hline & 89 & 87 & 98 & 92 & 90 & 80 & linker-5 \\
\hline & 87 & 71 & 89 & 87 & 61 & 72 & linker-6 \\
\hline & 94 & 82 & 79 & 85 & 2154 & 2280 & linker-7 \\
\hline & 75 & 66 & 1628 & 1594 & 81 & 83 & linker-8 \\
\hline & 98 & 103 & 71 & 84 & 69 & 85 & linker-9 \\
\hline & 102 & \begin{tabular}{|l|}
118 \\
\end{tabular} & 93 & 98 & \begin{tabular}{|l|}
113 \\
\end{tabular} & 99 & linker-10 \\
\hline \multirow[t]{10}{*}{ B } & 324 & 337 & 147 & \begin{tabular}{|l|}
148 \\
\end{tabular} & 5426 & 5366 & linker-1 \\
\hline & 101 & 102 & 93 & 88 & 86 & 74 & linker-2 \\
\hline & 111 & 119 & 119 & 123 & 66 & 72 & linker-3 \\
\hline & 72 & 65 & 59 & 68 & 74 & 67 & linker-4 \\
\hline & 81 & 98 & 83 & 92 & 79 & 72 & linker-5 \\
\hline & 90 & 84 & 93 & 86 & 70 & 76 & linker-6 \\
\hline & 101 & 105 & 101 & 97 & 956 & 944 & linker-7 \\
\hline & 82 & 83 & 189 & 204 & 97 & 90 & linker-8 \\
\hline & 92 & 83 & 78 & 64 & 82 & 78 & linker-9 \\
\hline & 83 & 79 & 88 & 93 & 4722 & 4965 & linker-10 \\
\hline \multirow[t]{10}{*}{ c } & 110 & 110 & 87 & 81 & 2114 & 2365 & linker-1 \\
\hline & 5526 & 5680 & 88 & 70 & 86 & 93 & linker-2 \\
\hline & 114 & 132 & 67 & 71 & 3326 & 3284 & linker-3 \\
\hline & 64 & 62 & 88 & 74 & 64 & 80 & linker-4 \\
\hline & 94 & 82 & 86 & 75 & 89 & 76 & linker-5 \\
\hline & 77 & 87 & 75 & 63 & 70 & 86 & linker-6 \\
\hline & 77 & 86 & 71 & 84 & 138 & \begin{tabular}{|l|}
121 \\
\end{tabular} & linker-7 \\
\hline & 73 & 86 & 80 & 79 & 59 & 73 & linker-8 \\
\hline & 86 & 74 & 5064 & 4923 & 88 & 86 & linker-9 \\
\hline & 105 & 113 & 85 & 80 & 124 & 114 & linker-10 \\
\hline \multirow[t]{10}{*}{ D } & 98 & 88 & 92 & 84 & 136 & 127 & linker-1 \\
\hline & 288 & 291 & 86 & 86 & 558 & 564 & linker-2 \\
\hline & 109 & 101 & 74 & 73 & 141 & $\mid 127$ & linker-3 \\
\hline & 78 & 66 & 66 & 55 & 74 & 66 & linker-4 \\
\hline & 79 & 83 & 79 & 86 & 96 & 91 & linker-5 \\
\hline & 83 & 86 & 96 & 89 & 86 & 73 & linker-6 \\
\hline & 87 & 89 & 77 & 87 & 841 & 855 & linker-7 \\
\hline & 74 & 72 & 60 & 72 & 90 & 95 & linker-8 \\
\hline & 68 & 75 & 331 & 328 & 2460 & 2580 & linker-9 \\
\hline & 86 & 98 & 80 & 75 & 123 & 133 & linker-10 \\
\hline \multirow[t]{3}{*}{$E$} & 101 & 114 & 101 & 106 & 532 & 548 & linker-1 \\
\hline & 101 & 96 & 110 & 104 & 682 & 675 & linker-2 \\
\hline & 6015 & 5988 & 124 & $\mid 126$ & $\mid$\begin{tabular}{|l}
$\mid 101$ \\
\end{tabular} & 98 & linker-3 \\
\hline
\end{tabular}




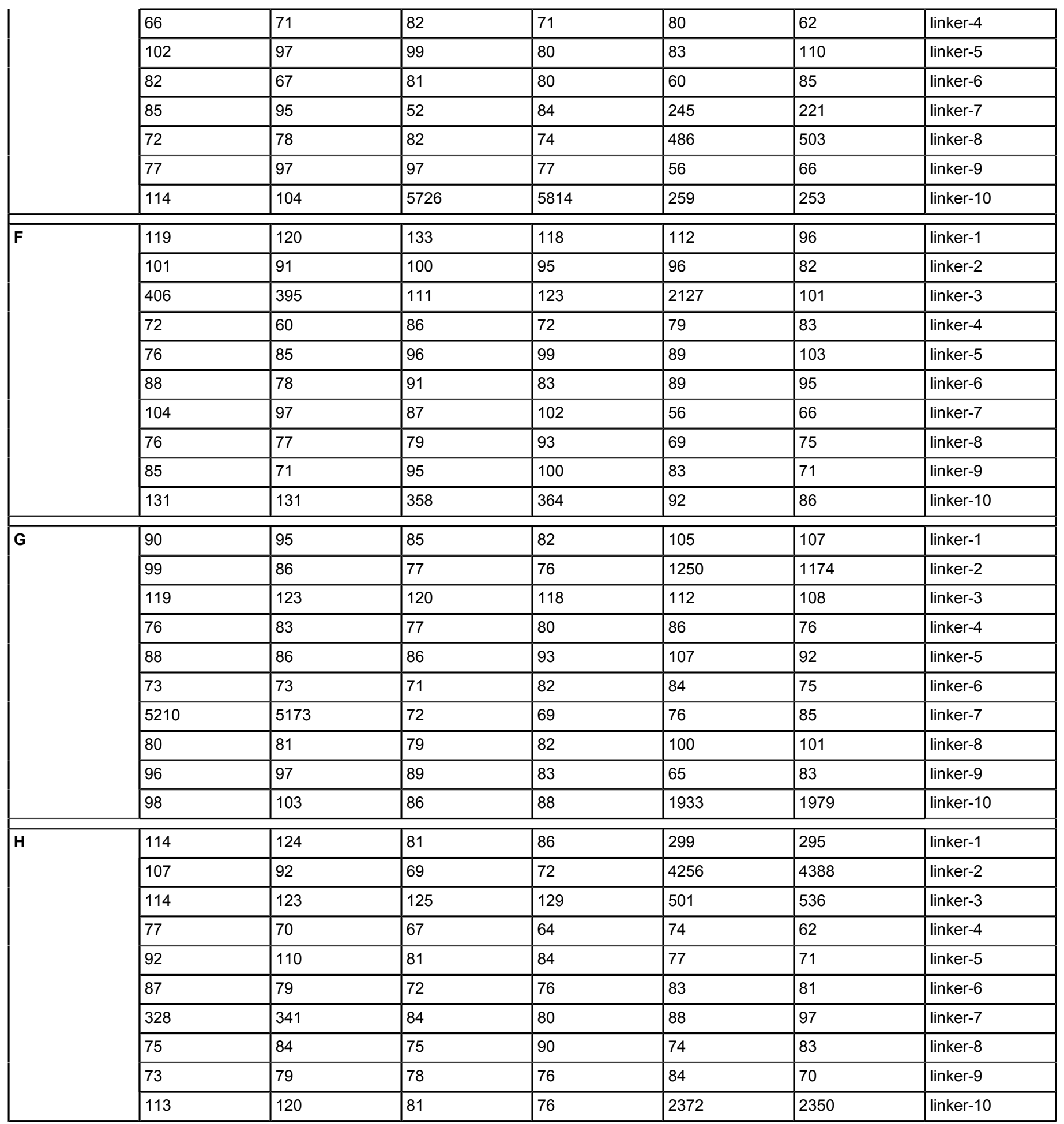

Table 1: Analysis of 7-plex ECL assay: raw CPS counts (left half of the plate). Raw CPS counts are acquired from an assay plate (the left half of the plate) and each sample is performed in duplicate. Under each row of the plate $(\mathrm{A}-\mathrm{H})$, there are 10 lines of reading values representing the data from the 10 spots within the same well, corresponding to each linker number as marked. Examples of bad duplicates are highlighted in grey, as seen in row F-linker 3-columns 5 and 6. 


\begin{tabular}{|c|c|c|c|c|c|c|c|c|c|}
\hline $\begin{array}{l}\text { Row of } \\
\text { Table 1A }\end{array}$ & $\begin{array}{l}\text { Column of } \\
\text { Table 1A }\end{array}$ & & linker 1 & linker 2 & linker 3 & linker 7 & linker 8 & linker 9 & linker 10 \\
\hline$A$ & $1-2$ & GADA PC & 5627 & 104 & 120 & 88 & 71 & 101 & 110 \\
\hline$B$ & $1-2$ & $\begin{array}{l}\text { GADA Low } \\
\text { PC }\end{array}$ & 331 & 102 & 115 & 103 & 83 & 88 & 81 \\
\hline$C$ & $1-2$ & TPOA PC & 110 & 5603 & 123 & 82 & 80 & 80 & 109 \\
\hline$D$ & $1-2$ & $\begin{array}{l}\text { TPOA Low } \\
\text { PC }\end{array}$ & 93 & 290 & 105 & 88 & 73 & 72 & 92 \\
\hline$E$ & $1-2$ & TGA PC & 108 & 99 & 6002 & 90 & 75 & 87 & 109 \\
\hline $\mathrm{F}$ & $1-2$ & TG Low PC & 120 & 96 & 401 & 101 & 77 & 78 & 131 \\
\hline $\mathrm{G}$ & $1-2$ & ThGA PC & 93 & 93 & 121 & 5192 & 81 & 97 & 101 \\
\hline $\mathrm{H}$ & $1-2$ & $\begin{array}{l}\text { ThGA Low } \\
\text { PC }\end{array}$ & 119 & 100 & 119 & 335 & 80 & 76 & 117 \\
\hline$A$ & $3-4$ & IAA PC & 111 & 102 & 112 & 82 & 1611 & 78 & 96 \\
\hline$B$ & $3-4$ & IAA Low PC & 148 & 91 & 121 & 99 & 197 & 71 & 91 \\
\hline$C$ & $3-4$ & IFNaA PC & 84 & 79 & 69 & 78 & 80 & 4994 & 83 \\
\hline$D$ & $3-4$ & $\begin{array}{l}\text { IFNaA Low } \\
\text { PC }\end{array}$ & 88 & 86 & 74 & 82 & 66 & 330 & 78 \\
\hline$E$ & $3-4$ & IA-2A PC & 104 & 107 & 125 & 68 & 78 & 87 & 5770 \\
\hline$F$ & $3-4$ & $\begin{array}{l}\text { IA-2A Low } \\
\text { PC }\end{array}$ & 126 & 98 & 117 & 95 & 86 & 98 & 361 \\
\hline $\mathrm{G}$ & $3-4$ & NC & 84 & 77 & 119 & 71 & 81 & 86 & 87 \\
\hline $\mathrm{H}$ & $3-4$ & NC & 84 & 71 & 127 & 82 & 78 & 77 & 79 \\
\hline A & $5-6$ & sample1 & 132 & 3851 & 119 & 2217 & 82 & 77 & 106 \\
\hline B & $5-6$ & sample2 & 5396 & 80 & 69 & 950 & 94 & 80 & 4844 \\
\hline C & $5-6$ & sample3 & 2240 & 90 & 3305 & 130 & 66 & 87 & 119 \\
\hline$D$ & $5-6$ & sample4 & 132 & 561 & 134 & 848 & 93 & 2520 & 128 \\
\hline$E$ & $5-6$ & sample5 & 540 & 679 & 100 & 233 & 495 & 61 & 256 \\
\hline $\mathrm{F}$ & $5-6$ & sample6 & 104 & 89 & 1114 & 61 & 72 & 77 & 89 \\
\hline G & $5-6$ & sample7 & 106 & 1212 & 110 & 81 & 101 & 74 & 1957 \\
\hline $\mathrm{H}$ & $5-6$ & sample8 & 297 & 4322 & 519 & 93 & 79 & 77 & 2361 \\
\hline
\end{tabular}

Table 2: Analysis of 7-plex ECL assay: arrangement of the Table 1 data, marked as 7 linkers. The data from Table 1 were rearranged, with linkers 4 through 6 (not used) deleted, and mean values were calculated from each duplicate reading from Table 1. The values of the internal standard high and low positive controls, corresponding to each autoantibody assay, restrained by a particular linker, are in dark bold. PC, positive control. NC, normal control. 


\begin{tabular}{|l|l|l|l|l|l|l|l|}
\hline & GAD-Index & TPOA-Index & TGA-Index & ThGA-Index & IAA-Index & IFNaA-Index & IA-2A-Index \\
\hline GADA PC & $\mathbf{1 . 0 0 0}$ & 0.005 & 0.000 & 0.003 & -0.006 & 0.003 & 0.004 \\
\hline GADA Low PC & $\mathbf{0 . 0 4 5}$ & 0.005 & -0.001 & 0.006 & 0.002 & 0.000 & -0.001 \\
\hline IAA PC & 0.005 & $\mathbf{1 . 0 0 0}$ & 0.001 & 0.002 & -0.001 & -0.001 & 0.004 \\
\hline IAA Low PC & 0.002 & $\mathbf{0 . 0 3 9}$ & -0.002 & 0.003 & -0.005 & -0.003 & 0.001 \\
\hline IA-2A PC & 0.004 & 0.004 & $\mathbf{1 . 0 0 0}$ & 0.004 & -0.004 & 0.000 & 0.004 \\
\hline IA-2A Low PC & 0.007 & 0.004 & $\mathbf{0 . 0 4 8}$ & 0.006 & -0.002 & -0.002 & 0.008 \\
\hline TGA PC & 0.002 & 0.003 & 0.000 & $\mathbf{1 . 0 0 0}$ & 0.000 & 0.002 & 0.002 \\
\hline TG Low PC & 0.006 & 0.004 & 0.000 & $\mathbf{0 . 0 5 2}$ & -0.001 & -0.002 & 0.005 \\
\hline TPOA PC & 0.005 & 0.005 & -0.001 & 0.002 & $\mathbf{1 . 0 0 0}$ & -0.002 & 0.001 \\
\hline TPOA Low PC & 0.012 & 0.003 & 0.000 & 0.006 & $\mathbf{0 . 0 7 6}$ & -0.003 & 0.001 \\
\hline ThGA PC & 0.000 & 0.000 & -0.008 & 0.001 & 0.000 & $\mathbf{1 . 0 0 0}$ & -0.001 \\
\hline ThGA Low PC & 0.001 & 0.002 & -0.008 & 0.002 & -0.009 & $\mathbf{0 . 0 5 0}$ & -0.002 \\
\hline IFNaA PC & 0.004 & 0.006 & 0.001 & 0.000 & -0.002 & 0.000 & $\mathbf{1 . 0 0 0}$ \\
\hline IFNaA Low PC & 0.008 & 0.004 & 0.000 & 0.005 & 0.004 & 0.002 & $\mathbf{0 . 0 4 8}$ \\
\hline NC & 0.000 & 0.000 & 0.000 & 0.000 & 0.000 & 0.000 & 0.000 \\
\hline NC & 0.000 & -0.001 & 0.001 & 0.002 & -0.002 & -0.002 & -0.001 \\
\hline sample1 & 0.009 & $\mathbf{0 . 6 8 3}$ & 0.000 & $\mathbf{0 . 4 1 9}$ & 0.001 & -0.002 & 0.003 \\
\hline sample2 & $\mathbf{0 . 9 5 8}$ & 0.001 & -0.008 & $\mathbf{0 . 1 7 2}$ & $\mathbf{0 . 0 0 9}$ & -0.001 & $\mathbf{0 . 8 3 7}$ \\
\hline sample3 & $\mathbf{0 . 3 8 9}$ & 0.002 & $\mathbf{0 . 5 4 2}$ & 0.012 & -0.009 & 0.000 & 0.006 \\
\hline sample4 & 0.009 & $\mathbf{0 . 0 8 8}$ & 0.003 & $\mathbf{0 . 1 5 2}$ & $\mathbf{0 . 0 0 8}$ & $\mathbf{0 . 4 9 6}$ & 0.007 \\
\hline sample5 & $\mathbf{0 . 0 8 2}$ & $\mathbf{0 . 1 0 9}$ & -0.003 & $\mathbf{0 . 0 3 2}$ & $\mathbf{0 . 2 7 1}$ & -0.005 & $\mathbf{0 . 0 3 0}$ \\
\hline sample6 & 0.004 & 0.002 & 0.169 & -0.002 & -0.006 & -0.002 & 0.000 \\
\hline sample7 & 0.004 & $\mathbf{0 . 2 0 5}$ & -0.002 & 0.002 & $\mathbf{0 . 0 1 3}$ & -0.002 & $\mathbf{0 . 3 2 9}$ \\
\hline sample8 & $\mathbf{0 . 0 3 9}$ & $\mathbf{0 . 7 6 8}$ & $\mathbf{0 . 0 6 8}$ & 0.004 & -0.001 & -0.002 & $\mathbf{0 . 4 0 0}$ \\
\hline
\end{tabular}

Table 3: Analysis of 7-plex ECL assay: results of index values. Index values for each sample for all 7 autoantibody assays were calculated against their corresponding internal positive and negative controls as described in the assay protocol. Any index value that was greater than the cut-off value was defined as a positive result, shown in dark bold. The TGA-index value of sample6 was highlighted in grey as it's an error caused by bad duplicates shown in row F-linker 3-columns 5 and 6 in Table 1.

\begin{tabular}{|l|l|l|l|l|l|l|l|l|l|l|l|l|l|l|}
\hline & \multicolumn{3}{|l|}{ GADA } & \multicolumn{1}{l}{ IA-2A } & \multicolumn{1}{l|}{ IAA } & \multicolumn{2}{l|}{ TGA } & \multicolumn{2}{l|}{ ThGA } \\
\hline & Sens & Spec & Sens & Spec & Sens & Spec & Sens & Spec & Sens & Spec & Sens & Spec & Sens & Spec \\
\hline RBA & $73.4 \%$ & $98.5 \%$ & $75.2 \%$ & $99.0 \%$ & $47.7 \%$ & $99.1 \%$ & $12.9 \%$ & $99.0 \%$ & $23.9 \%$ & $95.2 \%$ & $19.3 \%$ & $94.7 \%$ & $1.0 \%$ & $99.6 \%$ \\
\hline $\begin{array}{l}\text { Single } \\
\text { ECL }\end{array}$ & $71.6 \%$ & $99.1 \%$ & $73.6 \%$ & $99.3 \%$ & $48.3 \%$ & $99.7 \%$ & $16.0 \%$ & $98.9 \%$ & $26.3 \%$ & $94.9 \%$ & $20.6 \%$ & $95.1 \%$ & $0.8 \%$ & $99.2 \%$ \\
\hline $\begin{array}{l}7-P l e x \\
\text { ECL }\end{array}$ & $71.2 \%$ & $98.9 \%$ & $77.3 \%$ & $98.9 \%$ & $49.5 \%$ & $98.9 \%$ & $16.5 \%$ & $98.7 \%$ & $26.1 \%$ & $94.7 \%$ & $21.1 \%$ & $94.7 \%$ & $1.7 \%$ & $99.1 \%$ \\
\hline
\end{tabular}

Table 4: Assay sensitivity and specificity among 1026 T1D patients and 1022 controls, matched for both age and sex, in a 7-plex ECL assay, compared to the corresponding single ECL assay and RBA or ELISA*. Three different assays (RBA, single ECL and 7-Plex ECL) for each autoantibody were set to similar specificities using the 1022 age and sex matched healthy controls. The specificity outcome from the control cohort studied was set around $95 \%$ for TPOA and ThGA and at $99 \%$ for the 5 other assays. *Asterisk marks the IFNaA assay for ELISA, while others are RBA.

\section{Discussion}

In numerous national and international clinical trials for type 1 diabetes, the performance of the single ECL assay to detect islet autoantibodies and autoantibodies to transglutaminase (TGA) for celiac disease, has been substantiated ${ }^{8,9,10,11}$. Throughout these trails, this assay has increased the sensitivity and specificity for autoantigen detection when assessed against the existing 'gold' standard RBA. The enhanced disease specificity can be viewed when discriminating high-affinity and high-risk islet autoantibodies from low-risk, low-affinity signals, between the single ECL assay and the RBA ${ }^{14,15,16,17}$. Building on the single ECL assay, we pose a new high throughput multiplexed ECL autoantibody assay, to enable us to screen for T1D as well as several applicable autoimmune diseases at the same time. 
The multiplex ECL assay uses the multiplex plate, which can combine up to 10 autoantibody assays into one single well. For the present study, 7 autoantibody assays are combined together. The autoantibodies comprise of 3 IAbs (IAA, GADA, and IA-2A), 2 autoimmune thyroid disease autoantibodies (TPOA and ThGA), celiac disease autoantibodies (TGA), and APS-1 autoantibodies to interferon alpha (IFNaA). The assay mechanism is, in general, based on a single ECL assay as previously published ${ }^{9,10,12,18}$ with some modifications. The main difference of a multiplex ECL assay from a single ECL assay is that each antibody-antigen complex formed in the fluid-phase is restrained to a specific linker (Figure 1). The biotin labeled antigen is incubated with the Streptavidin conjugated, a linker used to form a specific antigen-linker complex. Antibody-antigen immune complex forms after incubation with patient serum and is captured onto a specific spot through the specific linker system on each well of the multiplex plate. Ru Sulfo-NHS labeled antigen captured by antibodies at the same time provides the signal with electrochemiluminescence. The plate reader machine can detect up to 10 different signals from the spot sources located in each well. To keep autoantibody assays consistent between plates and while conducting long-term studies, we suggest that the same linker is used.

Before setting up a multiplex ECL assay, single ECL assays for each autoantibody need to be optimized onto a multiplex plate, respectively, and validated against both RBA and single ECL assays on a regular ECL plate. To enhance the checkerboard assay, to the related autoantibody assay on the multiplex plate, a high positive patient and a negative patient sample were used. After the checkerboard assay was conducted, the most ideal concentrations for Ru Sulfo-NHS and biotin labeled antigen where calculated for each of the 7 autoantibody assays. The following shows these concentrations: $30 \mathrm{ng} / \mathrm{mL}$ and $200 \mathrm{ng} / \mathrm{mL}$ for GAD65, $120 \mathrm{ng} / \mathrm{mL}$ and $120 \mathrm{ng} / \mathrm{mL}$ for proinsulin, $10 \mathrm{ng} / \mathrm{mL}$ and $42 \mathrm{ng} / \mathrm{mL}$ for IA-2, $80 \mathrm{ng} / \mathrm{mL}$ and $80 \mathrm{ng} / \mathrm{mL}$ for TG, $8 \mathrm{ng} / \mathrm{mL}$ and $16 \mathrm{ng} / \mathrm{mL}$ for TPO, $31 \mathrm{ng} / \mathrm{mL}$ and $31 \mathrm{ng} / \mathrm{mL}$ for ThG, and $12 \mathrm{ng} / \mathrm{mL}$ and $12 \mathrm{ng} / \mathrm{mL}$ respectively for IFNa ${ }^{13}$. The concentrations of some of the antigens from the checkerboard assay may need to be further adjusted according to the outcomes in the actual multiplex assay after combining all of the assays together.

As IAA is included in the present multiplex ECL assay, acid treatment of serum samples is mandatory before incubating the serum with antigen as reported in the previous study ${ }^{12}$. Generally, when an extra autoantibody is added to a multiplex assay, the assay background is affected and an extremely high signal from one spot, in the well, may obstruct the results of nearby spots via crosstalk. Therefore, the maximum CPS needs to be limited to 20,000 counts for each autoantibody, or lower, for the highest positive samples. From our knowledge, in order to reduce the amount of crosstalk involved, autoantibodies that have a lower background should be separated, when designing the spot map, far from spots with a higher frequency of counts.

High positives and negative controls were used internally in every assay to calculate an accurate index for the unknown samples being tested. To accurately assess and monitor the assay's sensitivity, low positive controls, set near the assay's upper limit were used. These standard positive and negative controls were created in bulk and aliquot for long-term use and stored at $-20^{\circ} \mathrm{C}$ or below, for consistency between assays. For quality assurance purposes, samples were run twice in every assay and every positive result was reran and confirmed by running the sample in a new ECL assay the next day. If there was any disagreement with the first and second confirmatory assay, a third assay was necessary. Of the three assays conducted, the results of the two assays that agree (e.g., +, + or -,-), determined the final result (positive or negative) of the sample.

In the last decade, many study groups are seeking a high throughput assay utilizing the multiplex method to combine multiple autoantibody assays together into one well to screen large populations. There are a few studies that are using different types of technologies to conduct multiplex autoantibody assays ${ }^{19,20,21,22}$, but there is no comparison for any of these assays in sensitivity and specificity against the current 'gold' standard RBA, when studying T1D. These different types of platforms used are not validated through the international Islet Autoantibody Standardization Program (IASP) workshop or through testing large cohorts in clinical trials. In a recent general population-based screening in Germany, a high throughput combined assay, 3 Screen ICATM ELISA distributed by Kronus, is being used as a tool for first line screening to detect three IAbs, GADA, IA-2A, and ZnT8A, to achieve early diagnosis of childhood T1D ${ }^{23}$. The 3-Screen ELISA assay measures 3 autoantibodies either in 3 separated wells, consuming a large volume of serum, or in a single well with all 3 assays mixed. If one well in the $3-$ Screen ELISA assay is positive, one is unable to distinguish which of three autoantibodies are present. The biggest disadvantage of this assay is its inability to include IAA measurement. All IAA results performed by ELISA, as proven in IASP workshops, do not have an acceptable sensitivity and specificity ${ }^{24}$. IAA is usually the first IAb to appear and has a high prevalence among young children. IAb screening, with IAA, is necessary for children and it is not deemed acceptable to conduct this screening without IAA to asses T1D risk in the community. In addition, there are no published studies or data that show the Kronus IAb kit assay as being more T1D disease specific and able to discriminate high risk from low risk IAbs. The 7-Plex ECL assay, in the present study, was validated using a large cohort of newly diagnosed patients with T1D ${ }^{13}$. Compared with the current standard RBA and well-established single ECL assay, the 7-Plex assay is able to retain $100 \%$ positivity with the same assay specificity (Table 4). Currently, the 4-Plex ECL assay, parallel with the standard RBA, is being applied to an ongoing large clinical trial: Autoimmunity Screening for Kids (ASK) study. This trial screens children in the general population, of the Denver metropolitan area, for T1D and celiac disease. Compared to standard RBA used in the ASK study, the multiplex ECL assay is showing excellent sensitivity and a higher disease specificity, identical to our previous reports using the single ECL study ${ }^{25}$. Furthermore, our 4-Plex ECL assay demonstrated a pronounced reduction in labor, cost, and serum volume by $70 \%$, compared to the corresponding 4 single assays for ECL and RBA. Using the multiplexed ECL assay, we can customize each well with different numbers, representing different autoantibodies (up to 10), to test for different autoimmune diseases that are specific to the needs of a particular clinical location.

There are some limitations observed, shown in the present study, for a multiplexed ECL assay using the multiplex plate. The final dilution of serum, incubated with antigen, cannot be adjusted to yield the most optimal conditions for every single autoantibody assay that is combined in a single well. Nine samples (9/1026), from T1D patients, were observed to have a false negative result for particular autoantibodies. 7 of the false negatives were for TPOA and 2 were for ThGA, in the 7-Plex ECL assay, but high positive results were exhibited in both the single ECL assay and the RBA (Figure $2 \& 3$ ). After further dilution of all 9 samples, they became positive on the multiplex plate. This result is caused by, what we describe as the 'prozone' phenomenon. This phenomenon causes the sample to show a false negative result because the high antibody titers are affecting the formation of antigen-antibody lattices. When setting up a multiplex assay, samples with very high titers, for each of the combined autoantibodies, are recommended to have pre-tests ran to identify the optional dilution of serum for antigen incubation. Alternatively, autoantibody assays with similar optimized conditions should be selected to form a combined assay from which the best assay sensitivity and specificity is achieved for each autoantibody. In the present study, 7 samples (7/1022), from healthy normal controls, resulted in false positives for multiple autoantibodies in the 7-Plex assay, but after running a single ECL assay and RBA (Figure 2 \& 3 ) these autoantibodies were found to be negative in both assays. The reasons behind these false positive results occurring on the multiplex plate, for these small subset of samples, 
are currently unknown. For the current application of the multiplex ECL assay, all positive samples are repeated with their corresponding single ECL assay to confirm positivity, which removes this false positive error from the multiplex ECL assay.

\section{Disclosures}

The authors have nothing to disclose.

\section{Acknowledgments}

This work was supported by NIH grant DK32083, JDRF Grants 2-SRA-2015-51-Q-R and 2-SRA-2018-533-S-B.

\section{References}

1. Harjutsalo, V., Sjoberg, L., Tuomilehto, J. Time trends in the incidence of type 1 diabetes in Finnish children: a cohort study. Lancet. 371 (9626), 1777-1782 (2008).

2. Vehik, K. et al. Increasing incidence of type 1 diabetes in 0- to 17-year-old Colorado youth. Diabetes Care. 30 (3), $503-509$ (2007).

3. Atkinson, M. A., Eisenbarth, G. S., Michels, A. W. Type 1 diabetes. Lancet. 383 (9911), 69-82 (2014).

4. Insel, R. A. et al. Staging presymptomatic type 1 diabetes: a scientific statement of JDRF, the Endocrine Society, and the American Diabetes Association. Diabetes Care. 38 (10), 1964-1974 (2015).

5. Barker, J. M. et al. Autoantibody "subspecificity" in type 1 diabetes: risk for organ-specific autoimmunity clusters in distinct groups. Diabetes Care. 28 (4), 850-855 (2005).

6. Triolo, T. M. et al. Additional Autoimmune Disease Found in 33\% of Patients at Type 1 Diabetes Onset. Diabetes Care. 34 (5), $1211-1213$ (2011).

7. de Graaff, L. C., Smit, J. W., Radder, J. K. Prevalence and clinical significance of organ-specific autoantibodies in type 1 diabetes mellitus. Netherlands Journal of Medicine. 65 (7), 235-247 (2007).

8. $\mathrm{Yu}$, L. et al. Proinsulin/Insulin autoantibodies measured with electrochemiluminescent assay are the earliest indicator of prediabetic islet autoimmunity. Diabetes Care. 36 (8), 2266-2270 (2013).

9. $\mathrm{Yu}$, L. et al. Distinguishing persistent insulin autoantibodies with differential risk: nonradioactive bivalent proinsulin/insulin autoantibody assay. Diabetes. 61 (1), 179-186 (2012).

10. Miao, D. et al. GAD65 autoantibodies detected by electrochemiluminescence assay identify high risk for type 1 diabetes. Diabetes. 62 (12), 4174-4178 (2013).

11. Gu, Y., Zhao, Z., High, H., Yang, T., Yu, L. Islet Autoantibody Detection by Electrochemiluminescence (ECL) Assay. Journal of Clinical \& Cellular Immunology. 8 (6) (2017).

12. Gu, Y. et al. Electrochemiluminescence Assays for Human Islet Autoantibodies. Journal of Visualized Experiments. 10.3791/57227 (133) (2018).

13. Gu, Y. et al. High-throughput multiplexed autoantibody detection to screen type 1 diabetes and multiple autoimmune diseases simultaneously. Ebiomedicine. 47, 365-372 (2019).

14. Dongmei, M., A., K. S., Li, Zh., K. Michelle, G., Ling, J., Taylor, A. Electrochemiluminescence Assays for Insulin and Glutamic Acid Decarboxylase Autoantibodies Improve Prediction of Type 1 Diabetes Risk. Diabetes Technology \& Therapeutics. 17 (2), $119-127$ (2015).

15. Steck, A. K. et al. ECL-IAA and ECL-GADA Can Identify High-Risk Single Autoantibody-Positive Relatives in the TrialNet Pathway to Prevention Study. Diabetes Technology \& Therapeutics. 18 (7), 410-414 (2016).

16. Fouts, A. et al. Do Electrochemiluminescence Assays Improve Prediction of Time to Type 1 Diabetes in Autoantibody-Positive TrialNet Subjects? Diabetes Care. 39 (10), 1738-1744 (2016).

17. Sosenko, J. M. et al. The Use of Electrochemiluminescence Assays to Predict Autoantibody and Glycemic Progression Toward Type 1 Diabetes in Individuals with Single Autoantibodies. Diabetes Technology \& Therapeutics. 19 (3), 183-187 (2017).

18. Zhao, Z. et al. Higher Sensitivity and Earlier Identification of Celiac Disease Autoimmunity by a Nonradioactive Assay for Transglutaminase Autoantibodies. Journal of Immunology Research. 2016, 5 (2016).

19. Zhang, B., Kumar, R. B., Dai, H., Feldman, B. J. A plasmonic chip for biomarker discovery and diagnosis of type 1 diabetes. Nature Medicine. 20 (8), 948-953 (2014).

20. Tsai, C. T., Robinson, P. V., Spencer, C. A., Bertozzi, C. R. Ultrasensitive Antibody Detection by Agglutination-PCR (ADAP). American Chemical Society Central Science. 2 (3), 139-147 (2016).

21. Yim, S. W. et al. Four-color alternating-laser excitation single-molecule fluorescence spectroscopy for next-generation biodetection assays. Clinical chemistry. 58 (4), 707-716 (2012).

22. Bale, S. S. et al. A highly sensitive microsphere-based assay for early detection of Type I diabetes. Technology. 02 (03), 200-205 (2014)

23. Ziegler, A. G. et al. 3 Screen ELISA for High-Throughput Detection of Beta Cell Autoantibodies in Capillary Blood. Diabetes Technology \& Therapeutics. 18 (11), 687-693 (2016).

24. Schlosser, M. et al. Diabetes Antibody Standardization Program: evaluation of assays for insulin autoantibodies. Diabetologia. 53 (12), 2611-2620 (2010).

25. Zhao, Z. et al. A multiplex assay combining insulin, GAD, IA-2 and transglutaminase autoantibodies to facilitate screening for pre-type 1 diabetes and celiac disease. Journal of Immunological Methods. 430, 28-32 (2016). 